DOSSIÊ TEMÁTICO: Pesquisas em História da Educação: desafios passados e contemporâneos

dO https://doi.org/10.22481/praxisedu.v16i38.5990

\title{
ARACY CÔRTES E AS EXPERIÊNCIAS EDUCATIVAS DIFUSAS NOS PALCOS \\ AMADORES DO RIO DE JANEIRO (1900-1920)
}

\author{
ARACY CÔRTES AND DIFFUSED EDUCATIONAL EXPERIENCES IN THE AMATEUR
}

STAGES OF RIO DE JANEIRO (1900-1920)

\section{ARACY CÓRTES E LAS EXPERIÊNCIAS EDUCATIVAS DIFUSAS EN LOS PALCOS}

AFICIONADOS DEL RIO DE JANEIRO (1900-1920)

\author{
Rebeca Natacha de Oliveira Pinto \\ Universidade Federal Fluminense - Brasil
}

\begin{abstract}
Resumo: A partir da trajetória de Zilda de Carvalho Espindola (1904-1985), também conhecida como Aracy Côrtes, este trabalho se propõe a compreender as profundas relações entre educação - e suas práticas difusas -, cultura e política na cidade do Rio de Janeiro, nas primeiras décadas do século XX. Através de periódicos, entrevistas concedidas ao Serviço Nacional de Teatro e sua biografia, publicada em 1984, por Roberto Ruiz, busco perceber como as experiências dessa atriz, cantora e empresária do teatro de revista dialogavam com as transformações sociais ocorridas na capital federal. Debruçaremos-nos, especialmente, sobre suas vivências na Sociedade Dramática Particular Filhos de Talma, visto que os grêmios dramáticos vinculavam-se como espaços de formação social, promovendo práticas de letramento, palestras, encontros e debates de textos teatrais que permeavam o cotidiano da cidade. Para tanto, é importante concebermos a educação de forma ampla e plural, entendendo como as iniciativas pautadas em uma ação institucionalizada coexistiram com espaços plurais de acesso às letras. Como nos sugere Edward P. Thompson, ao considerarmos as diferentes vivências de Aracy Cortez no universo do entretenimento carioca, nos inclinamos a olhar para a sociedade na sua multifacetada rede de relações. Não obstante, o início de sua carreira artística nos permite perceber como as mulheres tornaram-se protagonistas de ações educativas, elaborando variadas estratégias para ampliar o acesso ao código letrado, conferindo-lhe uma vasta gama de sentidos.
\end{abstract}

Palavras-Chave: Gênero. Rio de Janeiro. Teatro Amador.

Abstract: From the trajectory of Zilda de Carvalho Espindola (1904-1985), also known as Aracy Côrtes, this work intends to understand the deep relations between education - and its diffuse practices -, culture and politics in the city of Rio de Janeiro, in the first decades of the twentieth century. Through periodicals, interviews given to the National Theater Service and his biography, published in 1984 by Roberto Ruiz, I try to understand how the experiences of this actress, singer and businesswoman of the magazine theater were in dialogue with the social transformations that took place in the federal capital. We will focus in particular on his experiences in the Particular Dramatic 
Society Sons of Talma, since the dramatic associations were linked as spaces of social formation, promoting practices of literacy, lectures, meetings and debates of theatrical texts that permeated the daily life of the city. Therefore, it is important to conceive education in a broad and plural way, understanding how the initiatives based on an institutionalized action coexisted with plural spaces of access to letters. As Edward P. Thompson suggests, when we consider the different experiences of Aracy Cortez in the universe of Carioca entertainment, we are inclined to look at society in its multifaceted network of relationships. Nevertheless, the beginning of her artistic career allows us to understand how women have become protagonists of educational actions, elaborating various strategies to expand access to the literate code, giving it a wide range of meanings.

Keywords: Gender. Rio de Janeiro. Amateur Theater.

Resumen: A partir de la trayectoria de Zilda de Carvalho Espindola (1904-1985), también conocida como Aracy Côrtes, este trabajo se propone a comprender las profundas relaciones entre educación -y sus prácticas difusas-, cultura y política en la ciudad de Río de Janeiro, las primeras décadas del siglo XX. A través de periódicos, entrevistas concedidas al Servicio Nacional de Teatro y su biografía, publicada en 1984 por Roberto Ruiz, busco percibir cómo las experiencias de esa actriz, cantante y empresaria del teatro de revista dialogaban con las transformaciones sociales ocurridas en la capital federal. En el caso de los gremios de Talma, los gritos dramáticos se vinculaban, como espacios de formación social, promoviendo prácticas de letra, charlas, encuentros y debates de textos teatrales que permeaban el cotidiano de la ciudad . Para ello, es importante concebir la educación de forma amplia y plural, entendiendo cómo las iniciativas pautadas en una acción institucionalizada coexistieron con espacios plurales de acceso a las letras. Como nos sugiere Edward P. Thompson, al considerar las diferentes vivencias de Aracy Cortez en el universo del entretenimiento carioca, nos inclinamos a mirar hacia la sociedad en su multifacética red de relaciones. No obstante, el inicio de su carrera artística nos permite percibir cómo las mujeres se convirtieron en protagonistas de acciones educativas, elaborando variadas estrategias para ampliar el acceso al código letrado, confiriéndole una amplia gama de sentidos.

Palabras Clave: Género. Rio de Janeiro. Teatro Aficionado.

\section{Introdução}

Neste trabalho, os primeiros passos artísticos de Zilda de Carvalho Espíndola (19041985), atriz, cantora e empresária do teatro de revistas carioca, serão explorados como um caminho possível para a compreensão das práticas educativas difusas que permeavam o universo do entretenimento no Rio de Janeiro nas primeiras décadas do século XX. Viso abarcar suas experiências no palco da Sociedade Dramática Particular Filhos de Talma, não perdendo de vista as inúmeras possibilidades de ocupação dos espaços públicos pelas mulheres no alvorecer do novecentos. Através das vivências e escolhas de vida dessa artista, que possuía a alcunha de Aracy Côrtes, busco apreender como as mulheres elaboraram variadas estratégias e ações para ampliar o acesso ao mundo das letras, construindo suas 
próprias interpretações sobre o letramento, e conferindo a educação uma vasta gama de sentidos.

Para a investigação da trajetória de Aracy Côrtes, a utilização instrumental do conceito de gênero faz-se extremamente importante. Inúmeros trabalhos acadêmicos buscaram ressignificar a atuação e experiências femininas. Segundo Joan Scott, o nascimento de um campo específico de pesquisa - História das Mulheres -, na Europa e nos Estados Unidos, relacionou-se à política - mais precisamente à política feminista que atingiu seu ápice entre os anos 1960 e 1970 (SCOTT, 1992). Estudos foram, pouco a pouco, revelando as inúmeras protagonistas sociais, tanto na esfera pública (motins, organizações políticas, imprensa, mercado de trabalho, entre outros espaços) como em aspectos privados relacionados à família, à maternidade e ao lar ( PERROT, 1988; THOMPSON, 1998).

A historiografia brasileira também produziu inúmeras reflexões sob a luz desses novos horizontes. Na década de 1980, houve uma efervescência ainda maior nas pesquisas, que passaram a investigar as mulheres enquanto sujeitos históricos, analisando seu cotidiano a partir das experiências sociais e ações de transformação da sua realidade (CUNHA, 1989; DIAS, 1984; ESTEVES, 1989; LEITE, 1984; LIMA, 1987; PENA, 1981; RAGO, 1985; SAMARA, 1989, SOHIET,1989; SOUZA, 1986; VAINFAS, 1989). Analisadas através da inovação e releitura das fontes (processos eclesiásticos e civis, obras literárias, tratados médicos e morais, imprensa, literatura de viagem, entre muitas outras) figuravam nas mais variadas abordagens temáticas tais como: sexualidade, família, moralidade, maternidade, feminismo e problematização dos estereótipos femininos (D'INCAO, 1989; DEL PRIORE, 1997; ENGEL, 1989; ALGRANTI, 1993; ALMEIDA, 1992; FIGUEIREDO, 1993; LENHARO, 1988; MOTT, 1987; MENEZES, 1992; PEDRO, 1994; QUINTANEIRO, 1996; RAGO, 1990; SOARES, 1992). Novas possibilidades para a percepção da participação das mulheres foram engendradas, tornando-as sujeitos sociais que lutavam contra as desigualdades de gênero e produziam suas próprias experiências.

Nesse viés, as escolhas realizadas por Zilda de Carvalho Espíndola nos trazem indícios para pensarmos as possibilidades e alternativas tangíveis às mulheres que, de diferentes maneiras, intentaram construir suas trajetórias no mundo do divertimento carioca. Rachel Sohiet nos adverte que devemos olhar para esse público em sua pluralidade, na divergência de posições, debates e controvérsias (SOHIET, 1998, p.83). As vivências da atriz, cantora e empresária ajudam a ampliar nossa compreensão de como liberdades sexuais estavam em 
disputa no alvorecer do século XX, uma vez que as mulheres, de diversos segmentos sociais, ocuparam o espaço público.

\section{Aracy Côrtes e a heterogeneidade das experiências femininas na cidade do Rio de Janeiro}

Aracy Côrtes nasceu no Rio de Janeiro, na capital federal, em 31 de março de 1904, filha de Argemira de Carvalho Espíndola e Carlos Espíndola. O casal já possuía dois filhos Silvino e Dalva - e morava na Rua do Matoso, bem próximo à região da Praça da Bandeira. Esta se constituía como um espaço usualmente utilizado pelos circos para montar suas lonas, como o Circo Spinelli, o Dudu Circo, entre outros. Anos depois, a família Espíndola se mudou para a Rua Magalhães, no bairro do Catumbi, sendo vizinha de Alfredo da Rocha Vianna (pai de Pixinguinha) ${ }^{1}$.

Carlos Espíndola, o pai de Aracy, nasceu em 1870 e morreu em 1920. Flautista, aprendeu a tocar com Antônio da Silva Salgado, professor da Escola de Música que morava próximo a sua residência. Como músico, Espíndola tornou-se figura constante em inúmeros bailes na Tijuca, Andaraí, Vila Isabel, Matoso e Itagipe, entre outras localidades do Rio de Janeiro, tocando choros, maxixes e lundus (RUIZ, 1984, p. 18).

A proximidade do pai com a música, no cotidiano do ambiente familiar, provavelmente ajudou a intensificar o interesse de Zilda pelas artes, uma vez que ele a levava para participar de encontros em que a música era frequente - alguns deles nas residências dos Rocha Vianna2 e de Tia Ciata3. Ruiz aponta que a "menina cresceu numa modesta casa, [...] encravada num bairro onde havia tocatas noturnas pelas ruas e onde se formaria a primeira escola de samba, sendo ainda um reduto de ciganos (1984, p. 13-14)”. Sabe-se também que sua irmã - Dalva Espíndola4 - foi artista do teatro de revista nos anos 1920, possibilitando-

\footnotetext{
1 Alfredo da Rocha Viana Filho nasceu na cidade do Rio de Janeiro (RJ) em 23 de abril de 1897 e morreu, na mesma cidade, em 1973. Foi compositor, arranjador, flautista e saxofonista brasileiro. É considerado um dos mais importantes compositores da Música Popular Brasileira. Ver: CABRAL, 2007.

${ }^{2}$ Família de Pixinguinha e vizinhos da família de Aracy Côrtes.

${ }^{3}$ Hilária Batista de Almeida, conhecida como Tia Ciata (Santo Amaro da Purificação, 1854 - Rio de Janeiro, 1924) foi uma cozinheira e mãe de santo brasileira, considerada por muitos como uma das figuras influentes para o surgimento do samba carioca. Sua casa reunia sambistas e foi palco da criação de "Pelo Telefone", o primeiro samba gravado em disco, assinado por Donga e Mauro de Almeida, na voz do cantor Baiano, também nascido em Santo Amaro da Purificação. Foi a mais famosa das tias baianas, em sua maioria iniciadas no Candomblé. Essas eram negras baianas que vieram para o Rio de Janeiro, especialmente na última década do século XIX e na primeira do século XX, para morar na região da Cidade Nova, do Catumbi, Gamboa, Santo Cristo e arredores. Ver: MOURA. 1995.

4 Atriz e cantora do teatro de revista, integrou a Companhia Negra de Revistas em 1926.
} 
me perceber como as experiências artísticas vivenciadas em sua família influenciaram as escolhas profissionais de ambas.

Em entrevista à Para Todos, em 07 de julho de 1924, ao ser perguntada sobre a sua infância, Aracy destacava que

Sou carioca. Nasci na Rua do Matoso, no dia 31 de março do ano da Graça de Nosso Senhor, o Samba. [...] Aos domingos sempre ia com a minha familia e amigos assistir as representações num Café Concérto que existia no Passeio Público. Garota ainda, estreei no Circo democrático, ao lado do saudoso Benjamim (PARA TODOS, 07/07/1924).

Ângela de Castro Reis, ao realizar um estudo sobre a formação de atores e atrizes, afirma que o núcleo familiar era "responsável pelo aprendizado artístico inicial". E que essas práticas vão sendo aprimoradas "no enfrentamento com o fazer teatral, ou seja, assimilando técnicas de atuação pela vivência das artes e não de um conjunto de conhecimentos formalizados a priori” (REIS, 2015, p. 01). Esses ensinamentos familiares se vinculam às tradições da comédia dell Arte, que são mantidas até os dias de hoje no circo, dialogando com outras experiências artísticas (FRANCA, 2016, p. 60).

Havia, assim, um legado artístico, uma "escola doméstica de formação, que é informal, construída a partir de uma vivência diária com as artes", como apontam os pesquisadores Mauro Meiches e Sílvia Fernandes (MEICHES; FERNANDES, 1999, p. 40). Dessa forma, antes das suas vivências em espaços educativos formais, Aracy Côrtes já vinha construindo, em uma profunda interlocução com o pai, músico, e a irmã mais velha, Dalva, diversas habilidades necessárias para o seu desenvolvimento como artista.

Penna Franca afirma que famílias de músicos e atores compartilhavam "palcos e ensinamentos teatrais, seja em função da ausência de uma escola dramática oficial ou porque o teatro se constituía como uma importante forma de lazer e convívio familiar e social” (FRANCA, 2016, p.60). Décio de Almeida Prado, em seu estudo sobre Procópio Ferreira, ressalta que, além das lições acerca da atuação em cena, também eram aprendidos em casa o respeito ao público, a disposição para a itinerância e a necessidade da disciplina. Nesse contexto, era "nas lições em família, que as atrizes, mais do que aprender a atuar, recebiam ensinamentos sobre a profissão, vista, principalmente, como um meio de sobrevivência - numa estreita relação com o público" (PRADO, 1993).

A vinculação entre educação e o espaço doméstico não era uma exclusividade do universo artístico e cultural. Não apenas porque muitos docentes faziam de sua própria casa um local institucionalizado de aprendizagem, mas também porque o lar era compreendido 
como um espaço no qual um conjunto de práticas educacionais eram vividas diariamente (VASCONCELOS, 2005, p. 16).

Para Maria Celi Vasconcelos, o ambiente doméstico consolidava-se como um primeiro espaço de socialização, no qual era possível “[...] estabelecer princípios morais, desenvolver, formar e instruir os sujeitos a partir dos conhecimentos acumulados pela humanidade, preparando-os para seus devidos papéis sociais" (VASCONCELOS, 2005, p. 205). Em casa, para além dos ensinamentos obtidos na escola, atividades educativas eram oportunizadas com a intenção de promover a manutenção dos valores de mundo às novas gerações, contando para isso com um vasto repertório pedagógico em circulação na imprensa do Rio de Janeiro (ANJOS, 2015, p. 55).

Luciano Mendes de Faria Filho, Marcus Aurélio Taborda de Oliveira e Liane Maria Bertucci contribuem uma compreensão da educação numa perspectiva vasta e plural. Para eles, a formação se faz numa tentativa de intervenção na cultura, a partir das lentes próprias do sujeito que se forma, seja ele individual ou coletivo (BERTUCCI; FARIA FILHO; OLIVEIRA, 2010, p. 74). Para Thompson, por sua vez, a formação implica em uma vontade de conhecimento que visa, em última instância, ao desencantamento do mundo, articulando uma profunda necessidade de autorreflexão crítica sobre as formas de organização da cultura (THOMPSON, 1989, Vol. III).

Raymond Williams, como outros autores do século XX, usa o termo cultura como "prática social" e "produção cultural", ambos entendidos como "sistema de significações" (WILLIAMS, 1992, p. 109). Para esse autor, cultura passou a incluir toda e qualquer "prática significativa", contemplando três dimensões antes desagregadas: como "modo de vida global", como "sistema de significações" e como "atividades artísticas e intelectuais" (WILLIAMS, 1992, p. 114). Esse conceito não exclui nenhuma dessas dimensões, e sim as agrega, as conjuga, pois tanto as produções artísticas, literárias e poéticas quanto as vidas ordinárias comuns são culturais, carregam em si significados e valores formulados no coletivo, nas interações humanas. É um espaço vivo, no qual as experiências são exploradas e vivenciadas. Nesse universo, educação, instrução e formação podem ser adicionadas como ingredientes importantíssimos na vivência da cultura.

A trajetória de Aracy Côrtes permite a apreensão de tais questões, uma vez que convida a reflexão sobre como o ambiente cultural e o espaço doméstico compuseram oportunidades de formação e desenvolvimento dessa artista teatral. Contudo, não desejo negligenciar suas vivências educacionais institucionalizadas. Em entrevista concedida a um 
projeto de construção de memórias dos artistas do teatro brasileiro, já com idade avançada, ela aponta que lhe foi proporcionada também uma vida escolar até o ensino secundário, custeada pela madrinha.

[...] Fui criada pela minha madrinha, uma senhora de alta sociedade, uma megera que me dava surras de meia-noite. Era uma criança marcada por beliscões. Mas o que ela me ensinou, aproveitei bem. Não completei curso nenhum, fui até o segundo ano ginasial [...]. Hoje tenho curso de inglês, de música e não me envergonho de minha gramática (BRASIL, 1977, p. 19-20).

Aracy experimentava, assim, possibilidades educacionais tangentes a inúmeras jovens nas primeiras décadas do século XX. Muitos estudos em história da educação têm salientado a pluralidade de experiências educativas de meninas e mulheres em diferentes grupos sociais, desde o século XIX (GONDRA; SCHUELER, 2008). Aponta-se ainda que

\begin{abstract}
Desde muito cedo, a aprendizagem prática das atividades cotidianas nas tarefas domésticas, na agricultura ou nos ofícios urbanos era prioritária. O trabalho feminino e a circulação das mulheres nas ruas e nos espaços públicos, na maioria dos casos em atividades do pequeno comércio (rendeiras, quitandeiras, ambulantes, costureiras, floristas, doceiras), e em atividades domésticas (criadas, lavadeiras, damas de companhia, amas de leite, copeiras etc.), no magistério (preceptoras, professoras das escolas e colégios particulares e públicos de primeiras letras, mestras de música, de artes, de produção de flores e objetos decorativos, de línguas estrangeiras etc.), na imprensa e no mundo das letras, além de outras inúmeras atividades, eram uma realidade incontestável nas principais cidades brasileiras do século XIX. Mesmo as mulheres pertencentes às elites, não raras vezes, na ausência dos pais, maridos, filhos ou outros responsáveis, assumiam a administração dos negócios familiares, seja no âmbito da produção doméstica, seja nas atividades de serviços urbanos (GONDRA; SCHUELER, 2008, p. 202).
\end{abstract}

Guacira Louro (1997) afirma que havia uma progressiva inserção das mulheres no mundo letrado, nas escolas e na profissão docente. Professoras, escritoras, jornalistas, artistas e intelectuais, em meio às desigualdades de gênero, se utilizaram das letras para redimensionar seus espaços de participação política. No campo da educação, tal questão é imperiosa, visto que grande parte das meninas e mulheres se fizeram professoras primárias ou preceptoras, atuando no magistério em escolas e colégios públicos ou particulares, evidenciando - ainda mais - a atuação feminina na esfera pública (SCHUELER, 2004).

$\mathrm{Na}$ entrevista transcrita anteriormente, Aracy Côrtes ressalta a importância dos ensinamentos obtidos no "ginasial", quando pode ampliar seu conhecimento em inglês e música, demonstrando ainda orgulho pela sua gramática. Gondra e Schueler apontam que 
saber ler e escrever vinculava-se ao pertencimento à modernidade, adquirindo grande importância para os diferentes grupos sociais (GONDRA; SCHUELER, 2008, p. 2017).

Schueler destaca que, a partir da segunda metade do século XIX, aulas e escolas primárias, colégios e educandários de ensino secundário e escolas normais foram sendo cada vez mais frequentados por meninas e mulheres (SCHUELER, 2004). Estas vivenciaram múltiplas práticas educativas, permitindo-me compreender a ampliação do acesso ao código letrado pelo público feminino. Escolas e colégios, religiosos ou leigos, existiram em diferentes localidades da cidade do Rio de Janeiro, reverberando as experiências das mulheres na luta por educação desde o oitocentos e intensificando a inserção deste grupo no ofício docente (LEITE, 1984).

Os embates por acesso à educação para meninas e mulheres se articulavam com as disputas pela ocupação do espaço público pela população feminina no alvorecer do século XX. A cidade em que Aracy cresceu passava por um intenso período de mudanças - não apenas do ponto de vista físico, mas também político, social e ideológico. Segundo Martha Abreu Esteves, a transformação da capital federal em uma cidade moderna e civilizada foi sendo entrelaçada com a construção de um discurso acerca de uma nova ordem social, de acordo com padrões cientificamente estabelecidos e com normas morais mais rígidas. A autora aponta que os juristas, em profícuo diálogo com os médicos, estavam empenhados em possibilitar a formação de um “cidadão completo, cumpridor de papéis interdependentes: trabalhador, membro de uma família e indivíduo higienizado (moradia, lazer e corpo saudáveis, por exemplo)" (ESTEVES, 1989, p.41).

$\mathrm{O}$ advento da República, as reformas urbanas implementadas na capital federal e a reconfiguração das hierarquias sociais, próprias do pós-abolição, engrossavam o caldo das muitas reivindicações femininas acerca da forma como as diferenças sexuais vinham sendo apropriadas pelas autoridades republicanas entre o final do século XIX e começo do século XX. Lerice Garzoni ajuda a perceber como, a despeito de um discurso de juristas e médicos, as mulheres conquistavam, cada vez mais, espaços na esfera pública - seja na escrita e publicação de periódicos, seja na organização de sociedades beneficentes, associações, entre outros (GARZONI, 2012, p. 34). Ampliavam-se as discussões na imprensa por um maior acesso a profissões usualmente ocupadas por homens (TEIXEIRA, 2010; PITA, 2009; MUZART; 2003; LEITE, 2003; CARULA, 2016; GARZONI, 2009; PINHEIRO, 2007; LENHARO, 1988). 
A exemplo da professora Leolinda Daltro e da líder operária Elisa Scheid, muitas mulheres se apresentaram de pena em punho demandando ações por igualdade de direitos, por cidadania plena e pelo maior acesso à educação (GARZONI, 2012, p. 116). Chamavam atenção por não pautarem suas experiências nos papéis de mãe e esposa. Entretanto, um bom número delas, tais como Júlia Lopes de Almeida, não elaborou seus discursos contrários a esse ideal, mas sim articulavam o casamento, a maternidade e sua missão civilizadora à necessidade de ampliar a educação e o trabalho femininos (ALMEIDA, 1897). Ora vistas sob o viés da fragilidade, ora afirmando-se como combativas, corajosas, responsáveis pela educação dos futuros homens da nação - ou ainda, como escritoras, trabalhadoras, operárias, advogadas -, as mulheres buscaram edificar múltiplas representações na imprensa carioca nas primeiras décadas republicanas (GUIMARÃES; FERREIRA, 2009; OLIVEIRA, 2009; SILVEIRA, 2015).

Assim, a trajetória de Zilda de Carvalho Espíndola evidencia as possibilidades de atuação feminina no espaço público carioca na Primeira República. Uma vez que diferentes mulheres ocupavam os palcos cariocas, reivindicando direitos e participação política, permitindo a interpretação do teatro como um ambiente privilegiado de reflexão e reverberação das transformações da sociedade. Ou seja, a cultura e as artes viabilizavam oportunidades tangíveis a muitas mulheres no início do novecentos - fossem como camareiras, atrizes, cantoras ou empresárias, entre outras. Maria Odila Dias salienta a necessidade da atenção à heterogeneidade das experiências históricas femininas na cidade do Rio de Janeiro entre o final do século XIX e as primeiras décadas do século XX (DIAS, 1994, p. 280).

A formação de Zilda de Carvalho Espíndola proporciona uma maior percepção da movimentação feminina pela capital federal nas primeiras décadas do novecentos. A artista cursou o ensino primário, tendo chegado até o secundário sob o patrocínio da madrinha. Acompanhava o pai nas apresentações musicais feitas por ele, participou de grupo de teatro amador - Sociedade Dramática Filhos de Talma - e compartilhou experiências no Democrata Circo, com Benjamin de Oliveira5, iniciando sua carreira de atriz e cantora. Ou seja, almejou conquistar seu lugar no mundo artístico, sendo essa sua opção profissional, não limitando seu horizonte e suas escolhas ao universo doméstico.

\footnotetext{
${ }^{5}$ Benjamin Chaves nasceu em Pará de Minas, em 11 de junho de 1870, e morreu no RJ, dia 03 de maio de 1954. Conhecido como Benjamin de Oliveira, foi um artista, compositor, cantor, ator e palhaço. Mais conhecido por ser o primeiro palhaço negro do Brasil, além de ser o idealizador e criador do primeiro circo-teatro. O sobrenome "Oliveira" veio após se inspirar no nome de seu instrutor, Severino de Oliveira. Ver: SILVA, 2007.
} 
Assim, ao debruçar-me sobre a trajetória de Zilda de Carvalho Espíndola, apreende-se como inúmeras possibilidades estavam em disputa, compreendendo que entre o lar e o ofício artístico nos palcos das revistas cariocas havia uma infinidade de nuances. Tais experiências emergem a fim de iluminar minha compreensão acerca das escolhas promovidas por essa atriz, cantora e empresária teatral. O Teatro amador foi meu ponto de partida para compreender os múltiplos espaços pedagógicos vivenciados por ela em sua construção como artista no teatro de revista no Rio de Janeiro na Primeira República.

\section{Se construindo atriz: as experiências na Sociedade Dramática Particular Filhos de Talma}

Em entrevista à revista Para Todos, em 07 de julho de 1932, quando é questionada sobre as suas primeiras experiências artísticas no universo do entretenimento carioca, Zilda de Carvalho Espíndola relata que essa iniciação aconteceu no teatro amador, na Sociedade Dramática Particular Filhos de Talma. Inaugurada em 1879, a associação está localizada no bairro da Saúde, na Rua do Propósito, $n^{\circ} 12 .{ }^{6}$

Escragnolle Doria, em uma publicação de 1943, destaca a "tradição carioca dos amadores" cultivada pela Sociedade Dramática Filhos de Talma (DORIA, 1943, p. 18). Ela homenageava o ator francês Francisco José Talma (1763-1826), que havia alcançado notoriedade na primeira metade do século XIX.

Os Filhos de Talma, em 1901, contava com mais de setecentos sócios. [...] Em 1918, mantinham importantes membros da diretoria com nacionalidade portuguesa como o próprio presidente Joaquim Dias Moreira, negociante, residente a rua do Livramento. Nessa mesa diretora encontramos mais dois portugueses, todos negociantes, e quatro brasileiros: um proprietário, um mecânico radio-telegrafista, um operário e ainda um empregado do comércio. (DORIA, 1943, p. 19).

O período em que a referida artista integra essa trupe de amadores, observa-se a pluralidade de grupos sociais que compunham esse espaço de convivência e desenvolvimento cultural existente na área central da cidade do Rio de Janeiro. A presença de negociantes e operários na organização e liderança da Filhos de Talma permite-me perceber a

\footnotetext{
${ }^{6}$ Torna-se importante destacar que essa instituição se encontra em funcionamento até os nossos dias. Mesmo possuindo algumas interrupções ao longo de sua história, está aberta como Centro Cultural, nos convidando a conhecer uma importante parte da história teatral do nosso país.
} 
heterogeneidade de seus integrantes, sendo provável a participação de muitos trabalhadores pobres, moradores das cercanias da agremiação.

Essa composição multifacetada se devia também ao bairro onde estava situada a associação. A Saúde se estabelecia na zona portuária, possuindo muitos habitantes que laboravam no porto, além dos inúmeros comerciantes existentes no local (MOURA, 1995). No final do século XIX e início do século XX, o bairro fazia parte da chamada "Pequena África", região da cidade que concentrava uma grande parcela da população mestiça e negra, e onde também morava Aracy Côrtes. Desse modo, era possível seu deslocamento até a Filhos de Talma para as aulas que eram ministradas naquele local, bem como para os ensaios dos espetáculos.

O periódico Almanack dos Theatros (1910, p.45) exaltava a notoriedade dos artistas amadores que compunham o elenco, "citados com respeito" por qualquer outra sociedade e também pelo número de atores, atrizes e músicos que passaram para o teatro profissional. $\mathrm{O}$ periódico enaltecia ainda o fato de terem sua sede em um edifício próprio e "uma das mais completas bibliotecas teatrais".

Os grêmios recreativos, para além de atividades artísticas, afirmavam-se como locais de auxílio mútuo aos diferentes trabalhadores e moradores que compunham a localidade a qual pertenciam. Cláudio Batalha, em seus estudos sobre associativismo operário, aponta como essas agremiações estabeleciam-se também como lócus de ação política (BATALHA, 2009, p.64). E ressalta o fato dessas sociedades terem um endereço permanente, evidenciando "solidez e uma tradição consolidada" (BATALHA, 2009, p.65). É possível afirmar que a "solidez e tradição" da Filhos de Talma tenha sido um dos motivos que permitiu a frequência de Aracy em suas aulas, cursos e espetáculos.

Muito mais do que simples associações recreativas, culturais ou dramáticas, essas organizações se constituíam como extraordinários ambientes de formação e exercício da cidadania. Necessitavam da “autorização da polícia para funcionar e, através das representações teatrais, da oferta de cursos e espaços de leitura e convivência, possibilitavam diálogos e debates acerca dos mais variados assuntos" (FRANCA, 2016, p. 43). Com isso, construíam ações coletivas, adotavam posições e pleiteavam questões que extrapolavam as próprias sedes, buscando espaços nas ruas da cidade.

Destaco essa experiência de formação vivida por Aracy Côrtes na Filhos de Talma, uma vez que, para além do ensino do código letrado, a artista pôde ampliar suas reflexões acerca das questões sociais, tanto a partir das peças que encenava quanto das obras literárias 
que lia - visto que a associação possuía uma enorme biblioteca (ALMANACK DOS THEATROS, 1910, p.45). Na referida entrevista à revista Para Todos, Aracy conta que possuía entre 15 e 16 anos quando passou a integrar essa agremiação, participando tanto das aulas que eram ministradas quanto do corpo cênico.

Educação, auxílio mútuo e lazer faziam parte do cotidiano das entidades amadoras, construindo redes de solidariedade e sociabilidades entre seus participantes. Assis Valente ${ }^{7}$, um dos integrantes do Club Dramatico Alumnos de Minerva e posteriormente um dos parceiros de Aracy Côrtes no teatro musicado, escreveu, no periódico publicado pelo clube, sobre a importância dessas sociedades:

A mocidade, por sua vez, compreendendo a utilidade da ideia, cumpriu com o seu dever, tratando de desenvolvê-la e ampliá-la - construíram-se edifícios apropriados, criando-se aulas onde empregam o tempo que lhes sobra dos labores cotidianos aqueles que desejam aperfeiçoar e completar a sua educação física e moral; hoje as sociedades recreativas erguem-se como um eloquente testemunho do quanto lhes devem o progresso material deste país e o desenvolvimento intelectual desta população.

Semelhante resultado enche de nobre e justo orgulho aqueles que contribuem com os seus esforços e sacrifícios para a existência dessas sociedades, porque se moralizar - ensinando é um importante serviço prestado às classes populares, não tem menos direito ao reconhecimento e à gratidão dessas mesmas classes os que se propõem civilizar recreando. (O PALLADINO, 1881, p. 01).

O teatro amador era uma alternativa extremamente presente no cotidiano carioca no início do novecentos, sendo vivenciado por grupos sociais heterogêneos e em espaços cênicos variados. O "teatrinho", como tantos jornalistas e intelectuais se referiam, assumiu múltiplas formas e ocupavam lugar significativo nas diferentes localidades da capital federal, concorrendo e disputando plateias com o teatro comercial. Segundo Thiago de Melo Gomes, a existência desses grupos dramáticos mostrava a força teatral nos bairros, revelando a importância dessa vertente cultural para a vida da cidade (GOMES, 2004).

No início do novecentos, período em que Aracy Côrtes vivencia suas experiências nos palcos amadores, observa-se uma grande quantidade de solicitações de licença para funcionamento, encaminhadas à polícia do distrito federal. Entre 1865 e 1920, é possível

\footnotetext{
7 José de Assis Valente (Santo Amaro,19 de março de 1911 - Rio de Janeiro, 6 de março de 1958) foi um ilustrador e compositor brasileiro extremamente presente nos palcos musicados da capital federal. Em 1927, muda-se para o Rio de Janeiro, tendo muitas composições que alcançam o sucesso, nas vozes de grandes intérpretes da época, como Carmen Miranda, Orlando Silva, Carlos Galhardo e muitos outros.
} 
verificar diferentes entidades amadoras, identificadas como grêmios, clubes, teatrinhos e sociedades amadoras, evidenciando também uma grande heterogeneidade dos agentes sociais que as compunham (FRANCA, 2011, p .36). Para Luciana Pena Franca,

Entre os grêmios encontrados em Botafogo, havia o Grêmio Amadoras da Flor de São João, que pretendia "ser dançante, recreativo e familiar", formado apenas por senhoras ligadas à Sociedade Musical Flor de São João. No Centro, a Estudantina Furtado Coelho também estava ligada ao Grêmio Dramático de mesmo nome que, segundo os estatutos, era quem determinava as regras para os dois grupos, sendo a diretoria formada pelas mesmas pessoas. Com características bem distintas de outros clubes, havia o Centro Galego, com sócios que deveriam ser de Galiza ou ser filho de pai galego apesar de aceitar os brasileiros, portugueses ou provenientes de outras províncias espanholas -, mas em categoria diferente dos primeiros. Os estatutos do Centro Galego são muito específicos em relação às homenagens, festas e atos patrióticos que deveriam cumprir; além disso, também tinham uma forte preocupação com a educação dos participantes e filhos de participantes. Outro clube cujo nome indica ser constituído por imigrantes, o Luzitano Club, no entanto, não fazia distinção de nacionalidade dos sócios. Uma preocupação comum de todos eles era com a criação de uma biblioteca para os associados. Essa preocupação também estava presente entre os membros do Recreio Dramático Juventude Portugueza e no Theatro Club ou no Grêmio Dramático Taborda, sediados no Centro do Rio de Janeiro. Ainda nessa área, encontrei, pelo menos, dois grupos mais ligados aos operários e seguidores da ideologia anarquista, que eram: o Grupo Dramático Teatro Livre e o Grupo Dramático Anti-Clerical (FRANCA, 2011, p. 37, grifo nosso).

Essas agremiações constituíam-se como espaços de formação social, promovendo práticas de letramento, palestras diárias, encontros e debates de textos teatrais que permeavam o cotidiano da cidade. Apesar de casos de clubes dramáticos que se organizavam nas casas dos sócios ou que usavam outros espaços para suas apresentações, havia muitos que possuíam sua própria sede - e nessas incluíam-se sala de teatro e biblioteca, bem como um espaço para encontros sociais e publicação de periódicos. Assim, a sede ajudava a construir a história da associação, consolidando sócios e viabilizando a participação cada vez maior dos habitantes do entorno - como foi o caso da Sociedade Dramática Particular Filhos de Talma e das experiências de Aracy Côrtes nas primeiras décadas do século XX.

Desde o século XIX, periódicos salientavam o papel pedagógico do teatro e sua função vinculada ao enaltecimento dos valores e da moral. O periódico $O$ Amador, do Club Dramatico Gonçalves Leite, localizado em São Cristóvão, afirmava: 
o Teatro é uma escola elevada, cuja missão é moralizar a sociedade ensinando-lhe como se desafronta graves ofensas, qual o fim sinistro de uma paixão ou vida desregrada, as flores que recebe os heróis do bem e os grilhões que o oprimem os heróis do mal (O AMADOR, 1888, p. 01).

O Espectador, em 1883, afirmava sua importância no cotidiano da cidade:

O teatro é a melhor tribuna, a melhor escola para combater e mostrar os vícios que corrompem uma sociedade. Por ele discute-se os mais difíceis problemas, e com vantagem, porque impressiona com arte o espírito do espectador, apresenta-nos sob a forma ridícula o vício; o perigo a que se expõem os que optam por semelhante mal, e discrimina as boas ações, os pequenos defeitos de educação de um povo e os próprios costumes que o orlam, dando uma perfeita fotografia dos elementos sociais, e são tratados na escola contemporânea pelo drama e pela comédia (O ESPECTADOR, 1883).

Observa-se como as interpretações acerca do papel educativo do fazer teatral estavam em debate na Primeira República, não havendo uma única concepção ou opinião para as atividades vivenciadas dentro dos clubes dramáticos. Muitos clubes amadores, como o Club Dramatico Alumnos de Minerva, entendiam o teatro como uma "influência benéfica e moralizadora", que atuava "nos costumes e na educação do povo", sendo um "poderoso elemento de civilização e progresso" (O PALLADINO, 1881, p.01). Nas palavras do referido jornal da agremiação, as "cenas passadas ao vivo nas tábuas do proscênio ${ }^{8}$ imprimem no espectador uma impressão mais violenta, e dão-lhe uma ideia mais exata, mais aproximada da execranda hediondez do vício e do crime, e do eterno triunfo da virtude e da justiça”. Os grupos teatrais anarquistas também evidenciavam sua intenção de educar o público acerca das doutrinas libertárias, afirmando a riqueza do teatro social, que combinava as intenções lúdica e doutrinária (HIPÓLIDE, 2012, p.55-56).

Tal questão poder ser comprovada pela criação de diversos espaços em que práticas de letramento eram experimentadas cotidianamente. Em 1925, período em que já fazia sucesso nos palcos profissionais, Aracy Côrtes retornou à sede da Sociedade Dramática Filhos de Talma para um evento de inauguração de uma sala de leitura, destacando a importância das vivências nessa associação para sua carreira artística. O Correio da Manhã publicava em 21 de agosto de 1925:

${ }^{8}$ Sinônimo de palco ou tablado. 
FILHOS DE TALMA - Está se preparando a velha agremiação recreativa carioca para proporcionar a seus frequentadores mais uma atraente festa no proximo domingo 23 do corrente.

Orientada por uma pleiade de cavalheiros de elevado tino administrativo a S.D.P. Filhos de Talma caminha hoje a passos agigantados para o auge de seu desenvolvimento máximo.

A sociedade passou por uma assombrosa metamorphose.

A installação de uma sala de leitura para os associados foi uma idéa feliz e de alcance, não sendo inferior a esta, a organização de torneios de football, pingpong, jogos passatempo e de outras diversões para os associados.

Os ensaios de dansa às quintas-feiras equivalem a verdadeiros bailes tal é a affluencia de socios e senhoritas.

A proxima festa constituirá, por certo, mais uma victoria de Filhos de Talma (CORREIO DA MANHÃ, 21 ago. 1925).

A inauguração de uma biblioteca ou sala de leitura é estabelecida nos "estatutos como um dos objetivos de grande parte dos associados ao lado das récitas e saraus dramáticos, juntamente com bailes, conferências, aulas, cursos e matinées para os filhos dos sócios" (FRANCA, 2016, p. 53). Tais espaços se constituíam como elementos que auxiliavam na formação artística de atrizes e cantoras, proporcionando o desenvolvimento do código letrado, assim como a troca e a fruição de saberes entre os diferentes participantes dessas trupes teatrais amadoras.

Sílvia Souza (2009) afirma que havia, então, uma valorização da leitura, da oratória, da declamação e isso não estava restrito a determinados bairros ou grupo social, pelo contrário, estava presente em praticamente todas as sociedades dramáticas encontradas. Ainda que houvesse associados analfabetos, o texto teatral impresso, por exemplo, foi escrito para ser lido "em voz alta, vislumbrando um tipo de leitura denominada intensiva, tais textos obedeciam a leis e regras próprias à transmissão oral e comunitária”, como afirma Sílvia Cristina Martins de Souza.

Ainda segundo a historiadora, a distância entre o texto representado e o texto impresso não era tão grande, "visto o uso de grifos, itálicos, provérbios e trocadilhos. Tais elementos, por sua vez, são indicativos dos dois tipos de relacionamento que tais textos estabeleciam com seus receptores (o espectador e o ouvinte), da sua dupla circulação (palco e página impressa) e de duas práticas de apropriação (a representação teatral e a leitura).

As atividades literárias iam muito além do saber dramático. Muitas agremiações realizavam aulas de português, inclusive em cursos noturnos para que um maior número de 
sócios pudessem frequentá-las. Apreende-se como esses espaços difusos de acesso ao código letrado somavam-se às múltiplas instituições escolares existentes na capital federal.

Laura Maciel salienta que, na última década do século XIX, a população do Rio de Janeiro era na ordem de 522 mil habitantes, dentre os quais 307 mil $(58,8 \%)$ afirmavam saber ler e escrever. Já nas primeiras décadas do século XX, com uma população beirando aos 900 mil habitantes, o índice de alfabetizados pairava em torno dos $61 \%$, ou seja, 540 mil habitantes (MACIEL, 2006, p. 283). Destaca-se que o Rio de Janeiro - sede da República Federativa do Brasil e que se propunha como uma das principais referências para os diferentes estados da federação - tinha uma população alfabetizada em números bastantes expressivos (MAGALDI; SCHUELER, 2009).

A população carioca, fosse por meio da dança, da música, da literatura, da produção de periódicos ou do teatro, "se reunia em seus bairros, junto a vizinhos, colegas de trabalho e familiares para, através de variadas formas de expressão, lutarem por reconhecimento, maior instrução, melhorias urbanas, sociais ou trabalhistas" (FRANCA, 2016, p.54). Buscavam assim, viabilizar um diálogo com as autoridades constituídas e exercitarem práticas de diversão entre eles próprios, construindo possibilidades para participação política e afirmação de sua cidadania no cotidiano da capital federal.

Evidencia-se as múltiplas práticas educativas difusas que permeavam o fazer teatral. Ainda que o teatrólogo escrevesse as peças com um viés atravessado de valores e de moral acerca de um determinado tema, não teria uma confirmação de que assim seriam compreendidas pelo público (MENCARELLI, 1999). Ou seja, diversas apreensões eram possíveis pelos diferentes grupos que compunham os espetáculos - fossem espectadores, diretores de cena ou ensaiadores. Podiam enfatizar aspectos do texto cênico e minimizar outros por meio da interpretação, da movimentação em cena e mesmo através dos cenários, ressaltando ou desaparecendo com objetos e imagens descritas inicialmente pelo autor. Para Franca:

[...] apesar da tentativa dos escritores para "educar" ou "civilizar" os espectadores com suas ideias, isso possibilitava diferentes leituras por parte da plateia. Se, para conquistar o público, as peças tinham que falar dos assuntos que incomodavam e que eram parte da vida deste público, então havia um diálogo aí entre textos, corpo cênico e plateias. Dessa forma, os efeitos estéticos e intelectuais dos significados produzidos através da leitura e interpretação de textos teatrais são múltiplos em função das diferentes formas de recepção e apropriação das suas mensagens (FRANCA, 2016, p. 186). 
O teatro profissional e as iniciativas de sociedades, clubes e associações dramáticas devem ser compreendidas como ações da sociedade civil na difusão do código letrado e possibilidades de acesso à educação para os diferentes grupos sociais. Não apenas porque foi uma das primeiras experiências artísticas de Aracy Côrtes, mas porque sua presença no cotidiano da cidade era extremamente significativa.

\section{Considerações Finais}

A trajetória dessa atriz, cantora e empresária teatral, com sua participação na Sociedade Dramática Filhos de Talma, aponta para o fato de que a educação não esgota seu significado na escola. José Gondra e Alessandra Schueler salientam a heterogeneidade das forças educativas, ampliando as percepções a respeito da "noção" de educação, visto que essa também "se processa no espaço privado, no convívio íntimo, nas leituras comuns, nas conversas, músicas, danças, festas, procissões e jogos" (GONDRA, SCHUELER, 2008, p. 10). Ana Luiza Costa mostra a importância de redimensionarmos a concepção de educação, uma vez que devemos olhar para "o educar-se como a experiência vivida, o ensinar e o aprender entre os próprios sujeitos populares, mesmo fora da escola, fosse em associações de trabalhadores, ou de forma mais difusa em seu cotidiano" (COSTA, 2012).

Dessa forma, afirmo que as atividades oportunizadas por esses clubes amadores visavam investir na formação de seus artistas, uma vez que instituíram e mantiveram escolas dramáticas, evidenciando as preocupações de tais instituições com o desenvolvimento do conhecimento cultural e técnico de seus integrantes (FRANCA, 2016, p. 183). A qualidade dessa formação era um cuidado contínuo, possibilitando um intenso trânsito de alguns artistas do teatro amador para o teatro comercial, como é o caso de Aracy Côrtes.

Infelizmente, não foram localizados, nas distintas fontes analisadas, os conteúdos programáticos das aulas, ou até mesmo o currículo das escolas dramáticas. No entanto, foram encontrados diferentes livros de artistas e teatrólogos, material referenciado nos periódicos como inspiração para os docentes, ensaiadores e diretores que trabalhavam nas diversas sociedades dramáticas amadoras. Entre eles estavam o Manual do Amador Dramático: Guia prático da arte de representar, escrito por Augusto Garraio ${ }^{9}$; Lições Dramáticas, de João

9 Escritor português nascido em 1843, atuou também como autor de peças de teatro. 
Caetano $^{10}$; e Para ser ator, de Eduardo Victorino ${ }^{11}$. Tais publicações buscavam fornecer estratégias para a realização dos melhores espetáculos, ensejando assim a qualidade teatral brasileira - no teatro amador ou profissional.

Para os autores, os atores deveriam saber aproveitar "os seus dotes, sujeitando-os, amoldando-os ao caráter da personagem escrita, mas imprimindo-lhe uma feição nova, sua, sem copiar ninguém" (GARRAIO, 1911). Deveriam estar atentos aos "rudimentos e regras necessárias a preparar o terreno para o estudo, com o qual descobrirão as dificuldades da cena" (CAETANO, 1956), assim como estudar "os planos da cena, os espaços do palco, como respirar e estudar um papel; combatendo, continuamente, o instinto de imitação, tendo como base suscitar-lhe a originalidade" (VICTORINO, 1936). Dessa forma, diferentes autores, nacionais e estrangeiros, articulavam-se na construção de uma literatura dramática que pudessem auxiliar na composição dos atores, produzindo apresentações de sucesso - para os amadores ou não.

Aracy Côrtes desfrutou dessas múltiplas experiências em sua formação - aulas de dança, de interpretação de textos e de leitura, entre outras - sendo essa etapa, em seu desenvolvimento como atriz, uma possibilidade vivida por muitos artistas nas primeiras décadas do século XX. Suas vivências no teatro amador duraram, aproximadamente, dois anos. Tais práticas se constituíram como uma valorosa etapa em sua formação, sendo até mesmo registrada em nota ao Correio da Manhã, em 08 de agosto de 1925.

Reforça-se aqui, mais uma vez, o papel pedagógico do universo teatral, em especial das práticas amadoras, que permitiam uma ampliação dos processos educativos de diversas artistas - fossem elas musicistas, dançarinas ou atrizes. Observa-se como as sociedades dramáticas amadoras oportunizavam diversas experiências formativas para meninas e mulheres de diferentes bairros da capital federal. Dessa forma, conseguimos compreender o início da carreira de Aracy Côrtes por esses palcos. Tais associações, possivelmente, faziam parte do cotidiano de divertimento e lazer de muitas famílias.

A Ephoca Theatral, em 22 de setembro de 1917, destaca que as mulheres tinham amplas possibilidades de acesso aos espetáculos teatrais espalhados pela cidade.

\footnotetext{
10 João Caetano dos Santos (Itaboraí, 27 de janeiro de 1808 - Rio de Janeiro, 24 de agosto de 1863) foi importante ator e encenador brasileiro. $\mathrm{O}$ ator também exerceu as funções de empresário e ensaiador. Autodidata da arte dramática, chegou a representar papéis cômicos. Além de atuar em muitas peças, João Caetano publicou dois livros sobre a arte de representar: Reflexões Dramáticas, de 1837, e Lições Dramáticas, de 1862.

${ }^{11}$ Escritor nascido em 1869, foi um ensaiador atuante na cena teatral brasileira no princípio do século XX. Era também empresário, dramaturgo e tradutor.
} 
[...] Nos subúrbios, onde muitos deles (amadores) existiram ou existem nesses palcos d'amadores dramáticos, não raras as organizações d'artistas se revelaram. Algumas delas são hoje, nos vários clubes ou no grande teatro, vultos queridíssimos pelos seus méritos. Podemos citar entre outras Lucilia, Carmen Azevedo, Cintra, etc. (EPHOCA THEATRAL, 22/09/1917).

Entre os nomes citados, salientam-se as artistas Cinira Polonio, Rosa Villiot, Ismenia dos Santos e Lucilia. Outras amadoras que se transferiram para os palcos comerciais são citadas por Arthur Azevedo em várias de suas crônicas publicadas em A Notícia: Italia Fausta e Guilhermina Rocha, além das portuguesas em terras cariocas: Maria Pinto, Luiza de Oliveira, Julia Moniz e Jesuína Saraiva (LEVIN; NEVES, 2009). Apreende-se como o caminho trilhado por Aracy Côrtes já havia sido percorrido por muitas outras atrizes na cidade do Rio de Janeiro nas primeiras décadas da República.

Na primeira metade do século XX, Aracy encenou mais de 100 peças teatrais, em inúmeras companhias - Companhia João de Deus, Empresa Paschoal Segretto, Companhia Tró-ló-ló, Companhia Luís de Barros, Ra-Ta-Plan, Empresa de M. Pinto Ltda., Companhia de Espetáculos Modernos, Companhia de Teatro Brasileiro -, sendo protagonista nos principais palcos da Praça Tiradentes e suas cercanias - Teatro Recreio, Teatro São José, Teatro São Pedro de Alcantara ( atual João Caetano) e Teatro Carlos Gomes. Construiu parcerias com os nomes mais consagrados no universo teatral carioca, tais como Luís Peixoto, Jardel Jércolis, Luís de Barros, Henrique Voleger, Marques Porto, Assis Pacheco, Freire Júnior, Carlos Bittencourt, Cardoso de Menezes, entre outros. E, em inúmeras composições, construiu, em diálogo com o público, diferentes possibilidades para ocupação feminina do espaço público.

Em tempos tão acirrados, em que a luta por direitos e protagonismos femininos se encontram em voga, compreender os processos de formação e as experiências artísticas de Aracy Côrtes são importantes para a ampliação da nossa percepção acerca da participação político-social das mulheres na sociedade brasileira, em meio às desigualdades de gênero. Da mesma forma, traz luzes para pensar como práticas educativas difusas se conjugam aos processos escolarização, nos permitindo perceber ainda como diferentes mulheres ascenderam socialmente através do ambiente cultural da cidade.

\section{REFERÊNCIAS}

ALGRANTI, Leila Mezan. Honradas e devotas: mulheres na colônia. Condição feminina nos conventos e recolhimentos do Sudeste do Brasil. Rio de Janeiro: José Olympio; Brasília: EDUNB, 1993. 
ALMEIDA, Ângela Mendes. O gosto do pecado. Rio de Janeiro: Rocco, 1992.

ALMEIDA, Julia Lopes de. Entre Amigas. In: A Mensageira: revista literária dedicada à mulher brasileira. 15 de out. de 1897.

ANJOS, Juarez José Tuchinski dos. A educação da criança pela família no século XIX: da historiografia a um problema de pesquisa. Rev. bras. hist. educ. v. 15, n. 1 (37), p. 51-81. jan./abr. 2015.

BATALHA, Claudio H. M. A geografia associativa: associações operárias, protesto e espaço urbano no Rio de Janeiro da Primeira República. In: AZEVEDO, Elciene et al (org.).

Trabalhadores na cidade: cotidiano e cultura no Rio de Janeiro e em São Paulo, séculos XIX e XX. Campinas: Editora da Unicamp, 2009.

BERTUCCI, Liane Maria; Faria Filho, Luciano Mendes; Oliveira, Marcus Aurélio Taborda de. Edward P. Thompson: história e formação, Belo Horizonte, Edufmg, 2010.

BRASIL. Depoimentos, v. III, FUNARTE/SNT, 1977

CABRAL, Sérgio. Pixinguinha: vida e obra. Rio de Janeiro: FUNARTE, 2007.

CAETANO, João. Lições Dramáticas. Rio de Janeiro: Ministério de Educação e Cultura, Departamento de Imprensa Nacional, 1956.

CARULA, Karoline. A imprensa feminina no Rio de Janeiro nas décadas finais do século XIX. Revista Estudos Feministas. v 24, n. 01, p. 261-279. janeiro-abril. 2016.

COSTA, Ana Luiza Jesus da. O educar-se das classes populares oitocentistas no Rio de Janeiro entre a escolarização e a experiência. 2012. 274f. Tese (Doutorado em Educação) Programa de Pós-Graduação em Educação da Faculdade de Educação, Universidade de São Paulo, São Paulo.

CUNHA, Maria Clementina Pereira. Loucura, gênero feminino: as mulheres de Juquery na São Paulo do início do século XVIII. Revista Brasileira de História. v.9, n.18, ago/set, 1989.

D’INCAO, Maria Ângela (org). Amor e família no Brasil. São Paulo: Contexto, 1989.

DEL PRIORE, Mary (Org.). História das mulheres no Brasil. São Paulo: Contexto, UNESP, 1997.

ENGEL, Magali. Meretrizes e doutores, saber médico e prostituição no Rio de Janeiro (1840-1890). São Paulo: Brasiliense, 1989.

DIAS, Maria Odila. Cotidiano e poder em São Paulo no século XIX. São Paulo: Brasiliense, 1984.

Novas subjetividades na pesquisa histórica feminista: uma hermenêutica das

diferenças. Estudos Feministas. v. 2, n. 2, p. 273-282.1994. 
DORIA, Escragnole. Teatro de amadores. Revista da Semana. 26 de junho de 1943.

ESTEVES, Martha de Abreu. Meninas perdidas: os populares e o cotidiano do amor no Rio de Janeiro da Belle Époque. Rio de Janeiro: Paz e Terra, 1989.

FIGUEIREDO, Luciano. O avesso da memória: cotidiano e trabalho da mulher em Minas gerais no século XVIII. Rio de Janeiro: José Olympio; Brasília: EDUNB, 1993.

FRANCA, Luciana Penna. Teatro amador: a cena carioca muito além dos arrabaldes. 2011. 118 f. Dissertação (Mestrado em História) - Instituto de Ciências Humanas e Filosofia, Universidade Federal Fluminense, Niterói.

Teatro Amador no Rio de Janeiro: associativismo dramático, espetáculos e periodismo (1871-1920). 2016. 244f. Tese (Doutorado em História) - Instituto de Ciências Humanas e Filosofia, Universidade Federal Fluminense, Niterói.

GARRAIO, Augusto. Manual do Amador Dramatico: guia pratico da arte de representar. $2^{\text {a }}$ ed. Lisboa, Arnaldo Bordalo: 1911.

GARZONI, Lerice de Castro. Nas fronteiras do não-trabalho: trabalhadores pobres e as definições de vadiagem no início do século XX. Revista Mundo do Trabalho, v. 1, p. 65-95. 2009.

Arena de combate: gênero e direitos na imprensa diária (Rio de Janeiro, início do século XX). 2012. 291f. Tese (Doutorado em História) - Instituto de Filosofia e Ciências Humanas, Universidade Estadual de Campinas (UNICAMP), Campinas.

GOMES, Tiago de Melo. Um Espelho no Palco. Campinas: Unicamp, 2004.

GONDRA, José Gonçalves; SCHUELER, Alessandra. Educação, poder e sociedade no Império Brasileiro. São Paulo: Cortez, 2008.

GUIMARÃES, Lucia Maria Paschoal; FERREIRA, Tânia Maria Tavares Bessone da Cruz. Myrtes Gomes de Campos: Pioneirismo na luta pelo exercício da advocacia e defesa da emancipação feminina. Revista do Instituto de Estudos de Gênero, v.9, n.2, p.135-151, Niterói, RJ, 1 sem. 2009.

HIPÓLIDE, Eduardo Gramani. O teatro anarquista como prática social do movimento libertário (São Paulo e Rio de Janeiro - de 1901 a 1922). 2012. 331f. Dissertação (Mestrado em História) - PUC-SP, São Paulo.

LEITE, Miriam L. Moreira. Outra face do feminismo: Maria Lacerda de Moura. São Paulo: Ática, 1984.

LEITE, Rosalina de Santa Cruz. Brasil Mulher e Nós Mulheres: origens da imprensa feminista brasileira. Revista Estudos Feministas. v. 11, n. 1, p. 234-241. 2003; 
LENHARO, Alcir. Fascínio e solidão: as cantoras do rádio nas ondas sonoras de seu tempo. Anais do Seminário Perspectivas do Ensino de História. São Paulo: Faculdade de Educação/USP, 1988.

LIMA, Lana Lage da Gama. (org). Mulheres, adúlteros e padres. Rio de Janeiro: Dois pontos, 1987.

LOURO, Guacira. Mulheres na sala de aula. In: DEL PRIORE, Mary (Org.). História das mulheres no Brasil. São Paulo: Contexto, UNESP, 1997.

MACIEL, Laura Antunes. De "o povo não sabe ler" a uma história dos trabalhadores da palavra. In: MACIEL, Laura Antunes; ALMEIDA, Paulo Roberto de; KHOURY, Yara Aun. (Orgs.). Outras histórias: memórias e linguagens. São Paulo: Olho d’água, 2006.

MAGALDI, Ana Maria Bandeira de Mello; SCHUELER, Alessandra Frota Martinez de. Educação escolar na primeira república: memória, história e perspectivas de pesquisa. Tempo. v.13, n.26, p.32-55. 2009.

MEICHES, Mauro, FERNANDES, Sílvia. Sobre o trabalho do ator. São Paulo: Perspectiva, 1999.

MENCARELLI, Fernando Antônio. Cena Aberta: A absolvição de um bilontra e o teatro de revista de Arthur Azevedo. Campinas: Editora Unicamp, 1999.

MOTT, Luiz. O lesbianismo no Brasil. Porto Alegre: Mercado Aberto, 1987;

MOURA, Roberto. Tia Ciata e a pequena África do Rio de Janeiro. 2a ed. Rio de Janeiro: Secretaria Municipal de Cultura, 1995.

MUZART, Zahidé Lupinacci. Uma espiada na imprensa das mulheres no século XIX. Revista Estudos Feministas. v. 11, n. 1, p. 225-233. 2003.

NEVES, Larissa de Oliveira; LEVIN, Orna Messer (Orgs.). O Theatro - crônicas de Arthur Azevedo. Campinas: Editora Unicamp, 2009.

OLIVEIRA, Karine da Rocha. Josephina Álvares de Azevedo: a voz feminina no século XIX através das páginas do jornal A Família. Rio de Janeiro: Fundação Biblioteca Nacional, 2009.

PEDRO, Joana Maria. Mulheres honestas, mulheres faladas: uma questão de classe.

Florianópolis: EDUSFC, 1994.

PENA, Maria Valéria Junho. Mulheres e trabalhadoras. Presença feminina na constituição do sistema fabril. Rio de Janeiro: Paz e terra. 1981.

PERROT, Michele. Os Excluídos - Operários, Mulheres e Prisioneiros. Rio de Janeiro: Editora Paz e Terra. 1988.

PINHEIRO, Alexandra Santos. Para além da amenidade — O Jornal das Famílias (18631878) e sua rede de produção. Tese (Doutorado em Teoria e História Literária) — Programa 
de Pós-graduação em Teoria e História Literária, Universidade Estadual de Campinas, Campinas, 2007.

PITA, Valéria. Nos termos de suas benfeitoras: encontros entre trabalhadoras e as senhoras da Sociedade de Beneficência, Buenos Aires, 1852-1870. Revista Mundos do Trabalho, v. 1, n. 2, p. 41-65. 2009.

PRADO, Décio de Almeida. Procópio Ferreira (Um pouco da prática e um pouco da teoria). In: Peças, pessoas, personagens: o teatro brasileiro de Procópio Ferreira a Cacilda Becker. São Paulo: Companhia das Letras, 1993.

QUINTANEIRO, Tania. Retratos de mulher: o cotidiano feminino no Brasil sob o olhar dos viajeiros do século XIX. Petrópolis: Vozes, 1996.

RAGO, Margareth. Do cabaré ao lar. A utopia da cidade disciplinar. Rio de Janeiro: Paz e Terra, 1985.

Unicamp, 1990.

Os prazeres da noite: prostituição e códigos da sexualidade feminina. Campinas:

SOARES, Luiz Carlos. Rameiras, ilhoas e polacas: A prostituição no Rio de janeiro do século XIX. São Paulo: Ática, 1992.

REIS, Ângela de Castro. Aprendizado atorial em âmbito familiar: paralelos entre o "teatro antigo" e o circo tradicional no Brasil. In: Anais do XXVIII Simpósio Nacional de História: Lugares de Historiadores: velhos e novos desafios. Florianópolis: ANPUH, UFSC, 2015.

RUIZ, Roberto. Araci Cortes: Linda Flor. Rio de Janeiro: Funarte, 1984.

SAMARA, Eni Mesquita. As mulheres, o poder e a família. São Paulo: Marco Zero, 1989.

SCHUELER, Alessandra Frota Martinez de. Notas sobre a feminização da docência: professoras primárias na cidade do Rio de Janeiro de fins do século XIX. Cadernos de Educação. ano 13, n. 22, jan./jun. 2004.

SCOTT, Joan. Gênero: uma categoria útil para análise histórica. Recife: SOS CORPO, 1992.

SILVA, Ermínia. Circo-teatro: Benjamim de Oliveira e a teatralidade circense no Brasil. São Paulo: Altana, 2007.

SILVEIRA, Daniela Magalhães da. O trabalho feminino no espaço doméstico: gênero e classe no Jornal das Famílias. Revista Topoi. v. 16, n. 31, p. 689-706. jul./dez. 2015.

SOIHET, Rachel. Condição feminina e formas de violência: mulheres pobres e ordem urbana 1890-1910. Rio de Janeiro: Forense Universitária, 1989. p.77-87, 1998.

História das mulheres e história do gênero. Um depoimento. Cadernos Pagu. n.11, 
SOUZA, Sílvia Cristina Martins de. Do tablado às livrarias: edição e transmissão de textos teatrais no Rio de Janeiro da segunda metade do século XIX. In: Anais do IV Congresso Internacional de História. Maringá: Universidade Estadual de Maringá, 9 a 11 de setembro de 2009.

TEIXEIRA, Roberta Guimarães. Na penna da imprensa professoras e professores primários do século XIX (1852-1888): contribuições aos estudos da feminização do magistério. 2010. 166f. Dissertação (Mestrado em Educação) - Programa de Pós-Graduação em Educação, Centro de Ciências Humanas e Sociais, UNIRIO, Rio de Janeiro.

THOMPSON, E. P. A formação da classe operária inglesa: a força dos trabalhadores. 2. ed. Rio de Janeiro: Paz e Terra, 1989.

As peculiaridades dos ingleses. In.: NEGRO, Antônio Luigi; SILVA, Sergio (orgs.). E. P. Thompson: As peculiaridades dos ingleses e outros artigos. 3. ed. Campinas: Unicamp, 1998. v. 1.

VAINFAS, Ronaldo. Trópicos dos pecados. Rio de Janeiro: Campus, 1989.

VASCONCELOS, Maria Celi. A casa e seus mestres: a educação no Brasil do Oitocentos. Rio de Janeiro: Gryphos, 2005.

VICTORINO, Eduardo. Para ser actor. $3^{\mathrm{a}}$ ed. São Paulo: Livraria Teixeira Vieira Pontes \& Cia, 1936.

WILLIAMS, Raymond. Cultura. Rio de Janeiro: Paz e Terra, 1992.

\section{SOBRE A AUTORA:}

\section{Rebeca Natacha de Oliveira Pinto}

Doutora em Educação da Universidade Federal Fluminense (UFF). Membro integrante do Grupo de Pesquisa em História Social da Educação. E-mail: rebecanatacha@ gmail.com.br

(iD) http://orcid.org/0000-0002-0482-888X 